\title{
Evaluation of potential applications of dietary probiotic (Bacillus licheniformis SB3086): Effect on growth, digestive enzyme activity, hematological, biochemical, and immune response of Tilapia (Oreochromis mossambicus)
}

\author{
Atif Yaqub $^{1, *}$ (D), Muhammad Nabeel Awan ${ }^{1}$ (D), Muhammad Kamran² (D), Iqra Majeed ${ }^{1}$ \\ ${ }^{1}$ Government College University, Department of Zoology, Fish Nutrition laboratory, Lahore, Punjab, Pakistan. \\ ${ }^{2}$ University of Sialkot, Department of Zoology, Sialkot, Punjab, Pakistan
}

How to cite

Yaqub, A., Awan, N.M., Kamran, M., Majeed, I., (2022). Evaluation of potential applications of dietary probiotic (Bacillus licheniformis SB3086): Effect on growth, digestive enzyme activity, hematological, biochemical, and immune response of Tilapia (Oreochromis mossambicus). Turkish Journal of Fisheries and Aquatic Sciences, 22(5), TRJFAS19882. http://doi.org/10.4194/TRJFAS19882

\section{Article History}

Received 27 August 2021

Accepted 20 December 2021

First Online 30 December 2021

\section{Corresponding Author}

Tel.: +923040420866

E-mail: nabeelawan120@gmail.com

\section{Keywords}

Bacillus licheniformis

Growth

Immunity

Hematology

Mozambique tilapia

\begin{abstract}
The present study was designed to evaluate the dietary effect of dietary supplementation of Bacillus licheniformis on growth, hematological and immune parameters of Oreochromis mossambicus fingerlings. A feeding trial of 8 weeks was carried out, in which fish were fed at a rate of $2 \%$ body weight with four experimental diets, including a control diet and three supplemented diets such as, $10^{5}, 10^{7}$ and $10^{9}$ $\mathrm{CFUg}^{-1}$ respectively. At the termination of feeding experiment, growth related parameters, hematological and immune response of fish were evaluated. Feed conversion ratio (FCR) was significantly decreased, inferring high efficiency in utilizing feed. In similar groups, hematological parameters such as total erythrocyte count, total leukocyte, total serum protein, blood glucose level and hemoglobin count were significantly increased $(\mathrm{P}<0.05)$, with higher probiotic concentration. Similarly, digestive enzyme activity of protease, lipase and amylase was also higher in fish fed with increased concentration of probiotic. Diet groups having $10^{9} \mathrm{CFUg}^{-1}$ of probiotic was observed with elevated immune response, as levels of lysozyme activity, respiratory burst activity and phagocytic activity were significantly higher $(P<0.05)$ in this group as compared to control group. In conclusion, supplementation of diet with Bacillus licheniformis can enhance growth performance, and health status of $O$. mossambicus
\end{abstract}

\section{Introduction}

Now-a- days, Aquaculture is one of the most expeditious meat production sectors and is the major source of availability of proteins to the society (Kamran et al., 2020). It is envisioned as a potential resource to address food and nutrition security in the future (Halwart, 2020). Fish farming accounts for $46.8 \%$ of total fish production in the world (FAO, 2020). Human population is growing at an exponential rate and annual fish growth rate has downturned in recent years which is worrisome. (Blanchard et al., 2012; Afridi et al., 2019). The declining global fish populations necessitates that aquaculturists strengthen their aquaculture practices to meet the increasing proteins demand (Ahmad et al., 2020; Naylor et al., 2021).

On a global basis, sustainable aquaculture with high rate of production is crucial for the survival of this sector (Bossier and ekasari, 2017). However, limitations of natural resources and impact on the environment are the challenges in the development of sustainable aquaculture industry (Carvalho et al., 2020; Bridson et al., 2020). In the recent few decades, there has been extensive influx of antibiotics in the aquatic bodies in pursuit of disease control. This situation has resulted in numerous environmental complications, such as drug 
resistance and bioaccumulation in aquatic life forms. There is a dire need to address this issue on urgent basis at not only in aquaculture industry but also in public health sector (Kim et al., 2017; Dawood et al., 2018; Adel and Dawood, 2021). Recently, use of probiotics has emerged as a reliable alternative which can mitigate the use of excessive antibiotics in aquaculture (Olmos et al., 2020; Won et al., 2020; Waiyamitra et al., 2020; Seethalakshmi, 2021). In aquaculture, probiotics have been used for a long time but in the last few years they have become an integral part of the growth promoting supplements and immune modulating additives. In fish aquaculture, probiotics administration supplemented with feed can inhibit growth of pathogens, modulate immunity, and enhance growth rate (Amir et al., 2019: Kuebutornye et al., 2020; Tachibana et al., 2021; Moustafa et al., 2021; El-Saadony et al., 2021; Liu et al., 2021; Hassaan et al., 2021). For example, Bacillus subtilis, Bacillus sp. KUAQ1 and Bacillus sp. KUAQ2 are reported to be potential probiotics known for their effect on growth enhancement and immune stimulation of Tilapia spp. fish (Sookchaiyaporn et al., 2020; Tachibana et al., 2021). These probiotics can alter the innate immune response; however, little is known about their effect on mucosal immunity in fish (Sheikhzadeh et al., 2012, Sutthi and Doan, 2020; Wang et al., 2020). Some probiotics, such as Bacillus spp., have also been known to enhance the antioxidant potential of various fish associated enzymes (Gobi et al., 2016).

Among the potential candidates of probiotics, gram-positive spore-producing bacteria belonging to the genus Bacillus spp. can be instrumental in fish aquaculture systems. Due to their resistant spores, they can withstand harsh environmental conditions. Also, they can produce important enzymes, such as lipase, protease, and amylase and are now emerging as one of the most widely used probiotics in aquaculture industry (Wang et al., 2019; Kuebutornye et al., 2020). Bacillus licheniformis is one of the promising candidates in this context (Mohammad et al., 2017; El-Sadoony et al., 2021) which can be isolated from soil, hot springs and from the feathers of ground dwelling birds, such as sparrows (Vigneshwaran et al., 2013). It is a gram positive, mesophilic bacterium which can survive at high temperatures; the optimal temperature for its growth is around $50^{\circ} \mathrm{C}$ (Kalishwaralal et al., 2009). It can produce antibacterial peptides in the intestinal tract of fish leading to better health and enhanced growth of fish (Jin et al., 2021). Bacillus licheniformis is also helpful as it is involved in the immunity boost in fish and tends to adhere to the gastrointestinal tract of fish and produces bacteriocins, thus reducing the the risk of infection there (Dawood and koshio, 2016). For instance, supplementary use of $B$. licheniformis at $1 \times 10^{5} \mathrm{CFU} / \mathrm{g}$ and $1 \times 10^{6} \mathrm{CFU} / \mathrm{g}$ use rates improved the growth, immune and antioxidant status of grass carp (Qin et al., 2020). Also, B. licheniformis BCR 4-3, with supplementation rate of $3 \times 10^{6} \mathrm{CFU} / \mathrm{L}$, has been reported to have a boosting effect on growth and survival of Litopenaeus vannamei. The same effect has been reported on sea cucumber, with optimal probiotic concentration of $10^{7} \mathrm{CFU} / \mathrm{g}$ (Garcia-medel et al., 2020; Lu et al., 2021).

On the other hand, omnivorous fish, such as Tilapia spp., are gaining rapid popularity particularly in Asian countries, such as Pakistan. Availability of Tilapia spp.in brackish and sea water resource in another reason why Tilapia spp. aquaculture trend is at the rise (Iqbal et al., 2012; Yaqub et al., 2019). To make this business viable, it is pertinent to prevent this fish from disease and avoid later economic losses (Zhang et al., 2013; Acar et al., 2015). Traditionally, various antimicrobials, parasiticides and feed additives are extensively used in the fish aquaculture (Naiel et al., 2020). However, there is a need to substitute this trend with probiotics to attain eco-friendly and more economic fish aquaculture system (Monica and Jayaraj, 2021). The current study was designed to analyze the effect of $B$. licheniformis on growth performance, digestive enzymes activity, hematological, biochemical, and immune parameters of Tilapia Mozambique (Oreochromis mossambicus).

\section{Materials and Methods}

\section{Experimental Fish}

Mozambique Tilapia (Oreochromis mossambicus) fingerlings were obtained from Manawan Fish hatchery, Lahore, Pakistan. After receiving the fish at the experimental location, the fish were acclimatized in concrete tanks (120L capacity) for 2 weeks under continuous flow of water. The temperature in the water tanks was maintained at $27 \pm 2.0^{\circ} \mathrm{C}, \mathrm{pH} 7.2 \pm 0.5$ and an average flow rate of $500 \mathrm{~L} \mathrm{~h}^{-1}$. During this period, the fish were provided $35 \%$ crude protein diet ( $2 \%$ of their body weight) and the fish health was monitored regularly by observing their skin and gill color, any external injuries, and symptoms of disease. Before the start of the experiment, fish were selected for the trial on the following basis: (a) No change in their skin and gills color (b) Skin with no sign of infection or bruise (c) Normal movement in flowing water (Strzyzewska et al., 2016, Strzyżewska et al., 2017; Basirun et al., 2019).

\section{Probiotic Culture}

The probiotic strain of $B$. licheniformis was isolated from soil and its molecular characterization was made by $16 \mathrm{~S}$ rDNA gene sequencing (NCBI GenBank accession no KT443923.1). This bacterium has been reported as probiotic in previous studies. In the current experiment, stock culture of the probiotic was used which had been previously maintained in sterile glycerol at $-20^{\circ} \mathrm{C}$ in the laboratory. For further experimental use, fresh cultures were prepared on agar plates. Then a single colony was inoculated in nutrient broth and was incubated overnight in shaker incubator. By preparing serial dilutions, colony forming units of the bacterium in each 
dilution were calculated by taking optical density (OD) at $600 \mathrm{~nm}$. The culture was centrifuged at $10,000 \mathrm{~g}$ for 20 minutes and pellets were resuspended in PBS for further use. Three concentrations of probiotic viz. 105 $10^{7}$ and $10^{9} \mathrm{cfu} \mathrm{g}^{-1}$ were used in experimental diets.

\section{Preparation of Experimental Diets}

The prepared concentrations of probiotic bacterium were mixed with basal diet (Table 1 ). The diets were converted into pellets. then air dried for 48 hours and stored at -4 으 for further experimental use. Survival of probiotic bacterium in the diet was assessed during the trial by preparing saline dilutions of the diet and plating $0.1 \mathrm{ml}$ of this dilution on nutrient agar plates at $36 \circ \mathrm{C}$ for 24 hours. The diets which retained the desirable colony count were used in the experiment.

\section{Feeding Schedule}

After the acclimatization period, healthy fish were transferred into aquaria that were triplicated for each diet. The control diet was, D1, having no probiotic, and the others, D2, D3, and D4 contained the experimental diets with $10^{5}, 10^{7}$, and $10^{9} \mathrm{cfu} \mathrm{g}^{-1}$, respectively. Each aquarium contained 15 fish; temperature and air quality of water in each aquarium was maintained according to standard conditions described previously. The experimental fish were provided basal diet and experimental diets for 8 weeks, twice daily. Continuous water exchange and removal of feces was done on regular basis to ensure best water quality in each aquarium.

\section{Growth Measurement}

Mean weight of fish in all aquaria was calculated before the feeding trial. After that, gross weight of equal number of fishes from each aquarium was calculated on weekly basis. At the end of trial, 5 fish from each aquarium (15 from each diet group) were randomly collected and their individual and mean body weight was calculated. Thereafter, growth parameters including percent weight gain (WG\%), specific growth rate (SGR\%), feed conversion ratio (FCR) and survival rate (\%SR) were calculated using the formulae already used by Zhou et al., (2013).

\section{Hematological Parameters}

After 8 weeks, five fish from each aquarium (15 from each diet group) were randomly collected and were anesthetized by MS-222 and blood was collected from caudal vein by using heparinized syringe and was stored in K2 VACUTTE ${ }^{\circledR}$ EDTA tubes. Then, using the already described protocol of Ullah et al. (2018), the hematological parameters, such as RBCs, WBCS, HCT, $\mathrm{HB}, \mathrm{MCH}, \mathrm{MCV}, \mathrm{MCHC}$ were determined.

\section{Intestinal Enzymes Activity}

At the end of the experiment, three fish per aquarium (nine fish/group) were used for intestinal enzymes activity analysis. For this purpose, the fish were anesthetized with MS-22, aseptically dissected at low temperature and their gastrointestinal tracts were removed carefully and snap frozen in nitrogen liquid and kept at $20 \circ \mathrm{C}$ for determination of Protease, Lipase and Amylase activities by using respective standard method (Amir et al., 2019; Ahmad et al., 2020).

\section{Biochemical and Immunological Parameters}

For biochemical and immunological parameters, the serum was collected from the blood of five fishes from each aquarium by using heparinized syringe in VACUTTE $^{\circledR}$ EDTA tubes (red top). Blood was centrifuged for 300 second at $3000 \mathrm{rpm}$; and serum was separated in microtube and stored at $4^{\circ} \mathrm{C}$. The method of Ullah et al. (2018) was adapted for the analysis of immunoglobulins, total serum protein, lysozyme, and amino transferase activity. Whereas, the respiratory burst and phagocytic activity was measured by using fresh heparinized blood (Devi et al., 2019).

Table 1. Formulation of feed and proximate composition of diets.

\begin{tabular}{lcccc}
\hline Ingredients & $\begin{array}{c}\text { Control D1(Inclusion } \\
\text { level } \mathrm{g} / 100 \mathrm{~g})\end{array}$ & $\begin{array}{c}\text { D2 (Inclusion } \\
\left.\text { level } 10^{5} \mathrm{~g} / 100 \mathrm{~g}\right)\end{array}$ & $\begin{array}{c}\text { D3(Inclusion level } \\
\left.10^{7} \mathrm{~g} / 100 \mathrm{~g}\right)\end{array}$ & $\begin{array}{c}\text { D4 (Inclusion level } \\
\left.10^{9} \mathrm{~g} / 100 \mathrm{~g}\right)\end{array}$ \\
\hline Fish meal & 18 & 18 & 18 & 18 \\
Soybean meal & 15 & 15 & 15 & 15 \\
Sunflower meal & 15 & 15 & 15 & 15 \\
Gluten 60 & 17 & 17 & 17 & 17 \\
Wheat bran & 17 & 17 & 17 & 17 \\
Rice bran & 15 & 15 & 15 & 15 \\
Vit. Premix & 1 & 1 & 1 & 1 \\
Fish oil & 1 & 1 & $10^{7}$ & \\
Cfu g-1 & 0.00 & $10^{5}$ & & \\
\hline Proximate Composition \%age & & & \\
\hline Crude Protein & 36.7 & & & \\
Crude Lipid & 9.1 & & & \\
Ash & 6.1 & & & \\
\hline
\end{tabular}




\section{Peroxidase Activity}

Peroxidase activity of serum was calculated by measuring its reduction capability towards hydrogen peroxide at 470nm (Civello et al., 1995).

The activity of peroxidase enzyme was measured using the expression given below:

$$
\operatorname{Activity}\left(\frac{\mathrm{Units}}{\mathrm{mL}}\right)=\frac{\Delta \mathrm{A} / 3}{26.6 \times 60 / 3000}
$$

\section{Glucose Content}

The blood sample was collected from fish and was centrifuged for 10 minutes at $10000 \mathrm{~g}$. The obtained serum was collected and incubated with glucose oxidase reagent for 30 minutes at $25 \circ \mathrm{C}$. Blood glucose concentration was determined by uning the following expression:

$$
\begin{gathered}
\text { Glucose concentration }=\text { Sample absorption }(470 \mathrm{~nm}) / \\
\text { Standard absorption } \times \text { Concentration of standard }
\end{gathered}
$$

\section{Challenge Test}

At the end of the experiment, 3 fish from each tank (9 from each diet group) were set for acclimatization for one week. All the groups were exposed to fresh culture of pathogenic bacteria, Staphylococcus aureus. Suspension of $S$. aureus were injected intraperitoneal to the fish at the concentration of $2.24 \times 10^{7} \mathrm{CFU} / \mathrm{g}$ suspended in PBS (Das et al., 2011). The bacterial strain was isolated from infected $L$. rohita at Institute of Industrial Biotechnology, GC University, Lahore. Challenge test study was conducted for 15 days. During that period, mortality as well as disease symptoms were observed closely in each group.

\section{Statistical Analysis}

One-way ANOVA, followed by LSD post-hoc test was performed to calculate significant difference between growth performance, hematological parameters, intestinal enzyme activity, biochemical and immunological parameters, etc. of different feeding groups. All statistical tests were performed using SPSS version 2.0. Significant level was set at $P<0.05$ and the results were presented as mean $\pm S D$. For graphical presentation GraphPad prism software version 5 was used.

\section{Results}

\section{Growth Performance}

Bacillus licheniformis-supplemented diet showed significant positive effect on the growth of Tilapia (Table 2). ANOVA revealed significant difference in final body weight ( $n=3$, ANOVA, $\left.F_{3,11}=96.4, \mathrm{P}<0.001\right)$, weight gain ( $n=3$, ANOVA, $\left.F_{3,11}=64.9, \mathrm{P}<0.001\right)$, weight gain percent $\left(n=3\right.$, ANOVA, $\left.F_{3,11}=6.15, \mathrm{P}<0.001\right)$, SGR $(n=3$, ANOVA, $\left.F_{3,11}=7.15, P<0.001\right)$, FCR $\left(n=3\right.$, ANOVA, $F_{3}, 11=109$, $P<0.001)$ and Survival percentage $(n=3$, ANOVA, $\left.F_{3,11}=54, P<0.001\right)$. The Post-hoc LSD test indicated high growth performance of probiotic- fed Tilapia as compared to the fish fed with control diet. Among probiotic-supplemented fed groups, the D4 (109 $\mathrm{cfu} / \mathrm{g})$ group showed maximum growth response, survival rate and lowest FCR.

\section{Hematological Parameters}

The probiotic, $B$. licheniformis-supplemented, fed groups showed significantly improved hematology parameters of Tilapia as compared to control (Table 3). ANOVA indicated significant differences in WBCs $(n=3$, ANOVA, $F_{3,11}=48.6, \quad \mathrm{P}<0.001$; Figure 1$)$, RBCs $(n=3$, ANOVA, $F_{3,11}=38.2, P<0.001$; Figure 1 ), blood glucose level ( $n=3$, ANOVA, $F_{3,11}=37.0, \mathrm{P}<0.001$; Figure 2$)$, HCT \% $\left(n=3\right.$, ANOVA, $F_{3,11}=47.1, \mathrm{P}<0.001$ (Table 3), $\mathrm{Hb}(n=3$, ANOVA, $F_{3,11}=18.7, \quad P<0.001$ (Table 3), $\mathrm{MCH}(n=3$, ANOVA, $F_{3,11}=40.8, \mathrm{P}<0.001$, (Table 3$)$ and $\mathrm{MCHC}(n=3$, ANOVA, $F_{3,11}=61.6, \mathrm{P}<0.001$ (Table 3). The Post-hoc LSD test indicated significantly varied hematological parameters of probiotic-fed Tilapia as compared to fish fed with control diet. Among groups fed upon probioticsupplemented diet, the D4 group $\left(10^{9} \mathrm{cfu} / \mathrm{g}\right)$ showed the highest concentration of $\mathrm{HCT}(\%), \mathrm{Hb}(\mathrm{g} / \mathrm{dl}), \mathrm{MCHC}\left(\mathrm{g} \mathrm{dL}^{-}\right.$ $\left.{ }^{1}\right), \mathrm{WBCs}, \mathrm{RBCs}$ and lowest concentration of $\mathrm{MCH}(\mathrm{pg})$ and blood glucose level.

Table 2. Comparative effects of dietary supplementation with the probiotic, Bacillus licheniformis, and control diet on growth and survival of Oreochromis mossambicus ( $n=3)$.

\begin{tabular}{lccccc}
\hline Test Diets & Diet 1 & Diet 2 & Diet 3 & Diet 4 & $P$-value \\
\hline Treatments & Control & $10^{5} \mathrm{CFU} / \mathrm{g}$ & $10^{7} \mathrm{CFU} / \mathrm{g}$ & $10^{9} \mathrm{CFU} / \mathrm{g}$ & \\
\hline Mean initial weight $(\mathrm{g})$ & $5.4 \pm 1.1$ & $5.3 \pm 0.9$ & $5.1 \pm 1.4$ & $5.3 \pm 1.2$ & \\
Mean final weight $(\mathrm{g})$ & $34.1 \pm 2.2^{\mathrm{d}}$ & $40.3 \pm 2.39^{\mathrm{c}}$ & $43.4 \pm 2.32^{\mathrm{b}}$ & $48.2 \pm 3.9^{\mathrm{a}}$ & 0.001 \\
Average weight gain $(\mathrm{g})$ & $28.7 \pm 1.9^{\mathrm{d}}$ & $35.0 \pm 2.11^{\mathrm{c}}$ & $38.3 \pm 3.1^{\mathrm{b}}$ & $42.9 \pm 4.05^{\mathrm{a}}$ & 0.001 \\
\% Weight gain & $533.2 \pm 66.4^{\mathrm{b}}$ & $667.8 \pm 59.9^{\mathrm{ab}}$ & $757.3 \pm 69.1^{\mathrm{a}}$ & $819.1 \pm 70.4^{\mathrm{a}}$ & 0.001 \\
SGR (\%) & $2.1 \pm 0.3^{\mathrm{b}}$ & $2.3 \pm 0.31^{\mathrm{ab}}$ & $2.4 \pm 0.32^{\mathrm{a}}$ & $2.5 \pm 0.23^{\mathrm{a}}$ & 0.001 \\
FCR & $1.4 \pm 0.2^{\mathrm{d}}$ & $1.3 \pm 0.27^{\mathrm{c}}$ & $0.9 \pm 0.21^{\mathrm{b}}$ & $0.7 \pm 0.1^{\mathrm{a}}$ & 0.001 \\
Survival Rate (\%) & $79.3 \pm 7.9^{\mathrm{c}}$ & $87.5 \pm 7.88^{\mathrm{b}}$ & $90.1 \pm 8.77^{\mathrm{b}}$ & $97.6 \pm 9.12^{\mathrm{a}}$ & 0.001 \\
\hline
\end{tabular}

One-way ANOVA followed by LSD Post-Hoc test shows a pairwise comparison between stocks. Variables in the same row with different superscripts are significantly different $(P<0.05)$ statistically. D1 fish group was fed upon basal diet, while D2, D3 and D4 groups were fed upon diet that included different levels of the probiotic, B. licheniformis: $10^{5} \mathrm{CFU} / \mathrm{g}, 10^{7} \mathrm{CFU} / \mathrm{g}$ and $10^{9} \mathrm{CFU} / \mathrm{g}$, respectively. 


\section{Intestinal Enzyme Activity}

Activity of protease, lipase, and amylase in the intestine of probiotic-fed groups was significantly higher as compared to the control group (Table 4). ANOVA revealed significant differences in protease activity $(n=3$, ANOVA, $\left.F_{3}, 11=46.4, P<0.001\right)$ (Table 4), Lipase $(n=3$, ANOVA, $F_{3,11}=54.7, \mathrm{P}<0.001$ (Table 4$)$, and Amylase $(n=3$, ANOVA, $F_{3}, 11=33.6, P<0.001$ (Table 4). Among the probiotic-fed groups, the D4 group $\left(10^{9} \mathrm{cfu} / \mathrm{g}\right)$ showed highest activity of protease, lipase and amylase.

\section{Immunological and Biochemical Parameters}

The probiotic-supplemented fed groups showed significantly improved results of immunological and biochemical parameters of Tilapia as compared to control (Table 5). One-way ANOVA suggested significant variation of total serum protein $\left(n=3\right.$, ANOVA, $F_{3,11}=15$, $P<0.001$ (Figure 2), total serum peroxidase activity $(n=3$, ANOVA, $\quad F_{3,11}=11.8, \quad \mathrm{P}<0.001, \quad$ (Figure 3), immunoglobulins $\left(n=3\right.$, ANOVA, $F_{3,11}=36.2, \quad P<0.001$ (Table 5$)$ and lysozyme activity $\left(n=3\right.$, ANOVA, $F_{3,11}=17.1$, $P<0.001$ (Table 5), respiratory burst $(n=3$, ANOVA, $F_{3,11}=75.0, P<0.001$ (Table 5), and phagocytic activity ( $n=3$, ANOVA, $F_{3}, 11=54.0, \mathrm{P}<0.001$ (Table 5). The posthoc LSD test indicated significant effect on biochemical and immunological parameters of probiotic-fed Tilapia as compared to the fish raised on the control diet. Amongst probiotic-supplemented fed groups, the D4 $\left(10^{9} \mathrm{cfu} / \mathrm{g}\right)$ group showed highest immunoglobulins $(\mathrm{mg} / \mathrm{ml})$, lysozyme activity $(\mu \mathrm{g} / \mathrm{ml})$, respiratory burst $(\%$ age) and phagocytic activity (\% age).

Table 3. Comparative effects of dietary supplementation with the probiotic, Bacillus licheniformis, and control diet on hematological parameters of Oreochromis mossambicus $(n=3)$.

\begin{tabular}{|c|c|c|c|c|c|}
\hline \multirow[t]{2}{*}{ Hematological Parameters } & \multicolumn{4}{|c|}{ Experimental Fish Groups } & \multirow[t]{2}{*}{$P$-value } \\
\hline & D1 & $\mathrm{D} 2$ & D3 & D4 & \\
\hline HCT (\%) & $26 \pm 1^{d}$ & $28.7 \pm 1.5^{c}$ & $33 \pm 1^{b}$ & $37.7 \pm 1.5^{a}$ & 0.001 \\
\hline $\mathrm{Hb}(\mathrm{g} / \mathrm{dl})$ & $6 \pm 0.8^{c}$ & $7.8 \pm 0.4^{b}$ & $8.6 \pm 0.1^{a b}$ & $9.9 \pm 0.9 \mathrm{a}$ & 0.001 \\
\hline $\mathrm{MCH}(\mathrm{pg})$ & $46.6 \pm 2.1^{a}$ & $42.3 \pm 0.6^{b}$ & $39 \pm 1^{c}$ & $34.4 \pm 1.5^{d}$ & 0.001 \\
\hline $\mathrm{MCHC}\left(\mathrm{g} \mathrm{dL}^{-1}\right)$ & $25.5 \pm 0.4^{d}$ & $26.6 \pm 0.5^{c}$ & $28.2 \pm 0.3^{b}$ & $29.6 \pm 0.4^{a}$ & 0.001 \\
\hline
\end{tabular}

One-way ANOVA followed by LSD post-hoc test shows pairwise comparison between the groups. Variables with different superscripts in the same row are statistically significantly different $(P<0.05)$. D1 group was fed on basal diet while D2, D3 and D4 fish groups were fed with diet that included different levels of the probiotic, Bacillus licheniformis: $10^{5} \mathrm{CFU} / \mathrm{g}, 10^{7} \mathrm{CFU} / \mathrm{g}$, and $10^{9} \mathrm{CFU} / \mathrm{g}$, respectively.
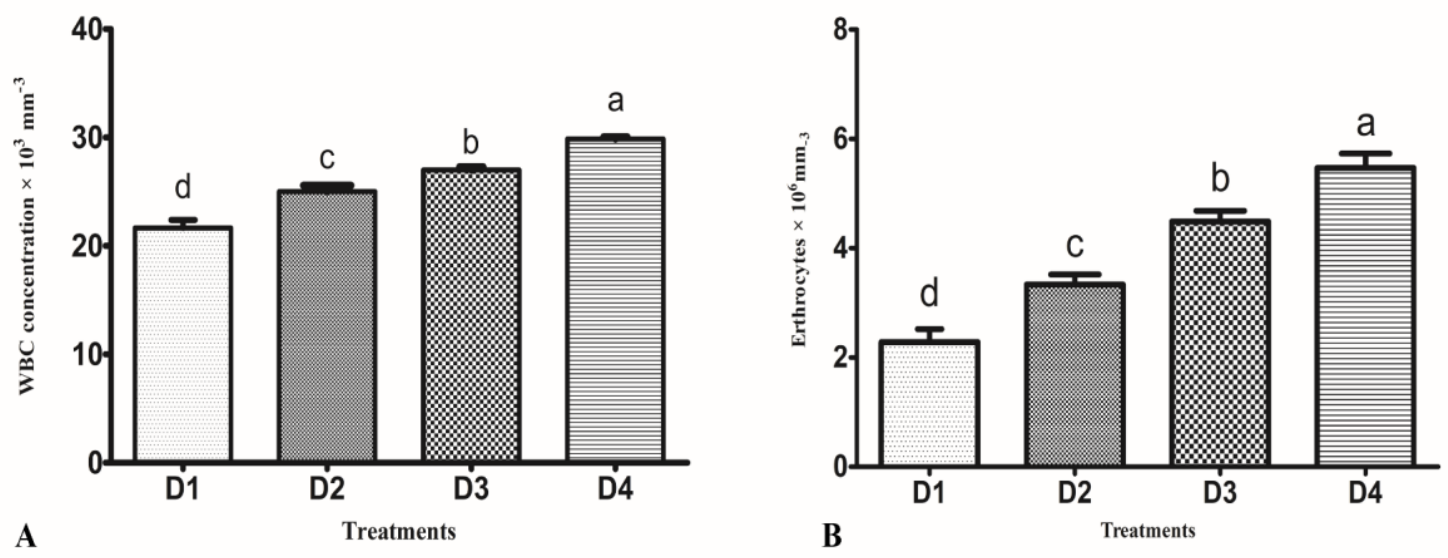

Figure 1. Effect of dietary Bacillus licheniformis supplementation on WBCs (A) and RBCs (B) of Tilapia fingerlings. Variables with different superscripts are significantly different statistically $(p<0.05)$. D1 fish group was fed on basal diet while D2, D3 and D4 groups were fed upon diets that included different levels of the probiotic, Bacillus licheniformis: $10^{5} \mathrm{CFU} / \mathrm{g}, 10^{7} \mathrm{CFU} / \mathrm{g}$, and $10^{9}$ CFU/g, respectively.

Table 4. Comparative effects of dietary supplementation with the probiotic, Bacillus licheniformis and control diet on activity of intestinal enzymes of Oreochromis mossambicus $(n=3)$.

\begin{tabular}{|c|c|c|c|c|c|}
\hline \multirow[t]{2}{*}{ Intestinal enzymes $\left(\mathrm{U} \mathrm{mg}^{-1}\right)$} & \multicolumn{5}{|l|}{ Experimental Fish Groups } \\
\hline & & & & & $P$-value \\
\hline & $\mathrm{D} 1$ & $\mathrm{D} 2$ & D3 & D4 & \\
\hline Protease activity & $9.7 \pm 0.5^{c}$ & $11.9 \pm 0.7^{b}$ & $13.0 \pm 0.4^{b}$ & $15.5 \pm 0.7^{a}$ & 0.001 \\
\hline Lipase activity & $2.5 \pm 0.2^{d}$ & $3.5 \pm 0.3^{c}$ & $4.6 \pm 0.3^{b}$ & $5.5 \pm 0.4^{a}$ & 0.001 \\
\hline Amylase activity & $1.5 \pm 0.3^{d}$ & $2.2 \pm 0.2^{c}$ & $2.7 \pm 0.2^{b}$ & $3.5 \pm 0.4^{a}$ & 0.001 \\
\hline
\end{tabular}

One-way ANOVA followed by LSD post-hoc test shows pairwise comparison between the groups. Variables with different superscripts in same row are significantly different statistically $(p<0.05)$. D1 fish group was fed on basal diet, while D2, D3 and D4 groups were fed on diet that included 


\section{Challenge Test}

The probiotic-fed group showed significantly lower mortality and higher survival percentage as compared to the control group. ANOVA indicated significant differences among all the groups $\left(n=3\right.$, ANOVA, $F_{3,11}=18$, $\mathrm{P}<0.001$ (Figure 4). The post-hoc LSD test indicated significantly higher survival percentage in D4 $\left(10^{9} \mathrm{cfu} / \mathrm{g}\right)$ group, followed by D3, D2 and D1 groups (Figure 4). Among probiotic-supplemented fed groups, the D4 (10 $\mathrm{cfu} / \mathrm{g}$ ) group showed highest survival percentage, and lowest mortality.

\section{Discussion}

The use of probiotics in aquaculture as dietary supplements with a view of eco-friendly and sustainable approach to enhance fish growth performance and health is gaining support based on substantial evidence. Some Bacillus species are promising candidates for their use in aquaculture (Doan et al., 2020; Monica and Jayaraj, 2021).

\section{Growth Performance}

The findings of present study suggest that inclusion of $B$. licheniformis in diet of $O$. mossambicus enhances its growth rate and immune response. The present study results strengthen previously reported findings concerning $B$. subtilis and $B$. licheniformis when incorporated in the fish feed resulting in higher growth, nutrient digestibility and higher protein efficiency ratio (Gobi et al., 2018; Romanova et al., 2020; Jin et al., 2021; Nayak, 2010). Also, some other previously performed studies suggest that probiotic supplemented diet can increase feed intake, production of vitamins, and can enhance the digestive activity of various enzymes (Gobi et al., 2018). Recently, inclusion of $B$. licheniformis in the diet of Cyprinus carpio and mrigal fry has been reported to result in better growth which report seems to strengthen the present study findings (Zhang et al., 2021).

\section{Feed Conversion Ratio (FCR)}

Inclusion of probiotics (Bacillus spp.) has been observed to result in better optimized FCR in Nile Tilapia (Oreochromis niloticus), which observation is in compliance with the results of previously performed similar studies showing optimal concentration of $10^{8}$ cfu/g for probiotic (Samson et al., 2020). Similarly, studies with grass carp (Ctenopharyngodon idella) have shown that the probiotic, $B$. subtilis-based diet resulted in improved FCR as compared to control group (Shah et al., 2021). A decreased value of FCR, is also a good sign that can be attributed to increase in the activity of digestive enzymes, intestinal health, and decrease in stress levels in culture environment. Also, improved FCR can be seen as $O$. niloticus gains maturity, owing to

Table 5. Comparative effects of dietary supplementation with the probiotic, Bacillus licheniformis, and the control diet on biochemical and immunological parameters of Oreochromis mossambicus $(n=3)$.

\begin{tabular}{|c|c|c|c|c|c|}
\hline Biochemical and Immunological Parameters & Experimental Fish Groups & & & & $P$-value \\
\hline & D1 & D2 & D3 & D4 & \\
\hline Immunoglobulins (mg ml-1) & $7.7 \pm 0.2^{d}$ & $8.9 \pm 0.7^{c}$ & $10.6 \pm 0.4^{b}$ & $11.6 \pm 0.5^{a}$ & 0.001 \\
\hline Lysozyme activity $\left(\mu \mathrm{g} \mathrm{ml}^{-1}\right)$ & $7.8 \pm 0.4^{c}$ & $9.2 \pm 0.6^{b}$ & $10.3 \pm 0.4^{\mathrm{ab}}$ & $11.1 \pm 1.0^{\mathrm{a}}$ & 0.001 \\
\hline Respiratory burst (\%age) & $0.3 \pm 0.2^{c}$ & $0.6 \pm 0.1^{b}$ & $1.1 \pm 0.1^{b}$ & $2.1 \pm 0.2^{\mathrm{a}}$ & 0.001 \\
\hline Phagocytic activity (\%age) & $1.5 \pm 0.4^{d}$ & $2.3 \pm 0.1^{c}$ & $2.8 \pm 0.1^{b}$ & $3.7 \pm 0.3^{a}$ & 0.001 \\
\hline
\end{tabular}

One-way ANOVA followed by LSD post-hoc test shows pairwise comparison between the groups. Variables with different superscripts in the same row are significantly different $(P<0.05)$ statistically. D1 fish group was fed on basal diet, while D2, D3 and D4fish groups were fed upon diet that included different levels of the probiotic, Bacillus licheniformis: $10^{5} \mathrm{CFU} / \mathrm{g}, 10^{7} \mathrm{CFU} / \mathrm{g}$ and $10^{9} \mathrm{CFU} / \mathrm{g}$, respectively.
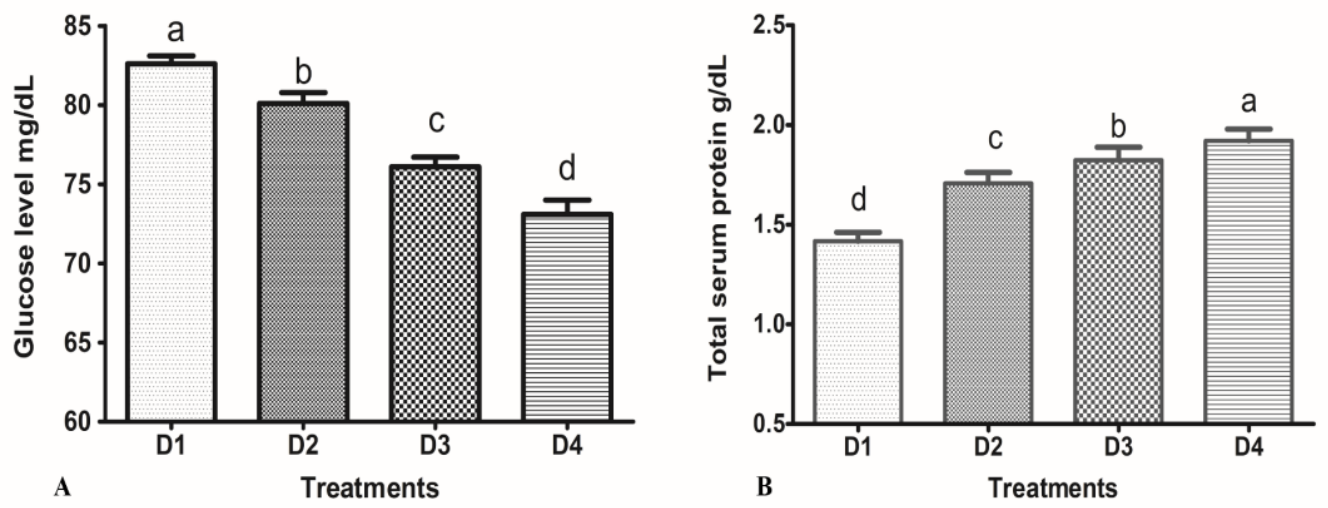

Figure 2. Effect of dietary Bacillus licheniformis supplementation on blood glucose level (A) and total serum protein (B) of Tilapia fingerlings. Variables with different superscript are significantly $(p<0.05)$ different statistically. D1 group was fed upon basal diet, while D2, D3 and D4 groups were fed upon diets including different levels of the probiotic, Bacillus licheniformi:105 CFU/g, 107 $\mathrm{CFU} / \mathrm{g}$ and $10^{\circ} \mathrm{CFU} / \mathrm{g}$, respectively. 
improvement in its digestive system (Rodde et al., 2020). Thus, probiotics in diet can cause modifications gut flora of fish as well as simulate digestive activity beneficial for efficient utilization of biomolecules in feed (Amir et al., 2019).

\section{Immune Modulation}

Modulation of immune response by use of probiotics is also a well-documented fact. Alteration of immune response takes place by adhesion and colony formation by probiotics in fish intestine. Probiotics and immune system interact through microbially- associated molecular patterns which involve peptidoglycan and lipoteichoic acid. This interaction takes place by various types of receptors, such as Tol-like receptors. Probiotic can enhance immune activity in fish by interacting with various types of immune cells (Gobi et al., 2018). Some previous studies have also suggested an increase in serum and mucus protein in Labeo rohita and Catla catla treated with different types of probiotics, such as $B$. subtilis and B. amyloliquifaciens (Mohapatra et al. 2012; Sutthi and Doan, 2020). Similarly, in the present study, the total serum protein concentration was observed to higher in O. mossambicus treated with the probiotic $B$. licheniformis Dahb1 diets. These proteins are known for their association with lysozymes, immunoglobulins and lectins which are important in the defensive mechanism against pathogens. The present study suggests that supplementation of 0 . mossambicus diet with $B$. licheniformis, can improve the concentration of serumassociated proteins, thereby resulting in increased serum proteins level.

\section{Hematological Parameters}

Administration of probiotics can increase white blood cells count in fish which is also associated with enhanced immunity. Oreochromis. niloticus supplemented diet with Bacillus pumilus (Aly et al., 2008) and Nile Tilapia fed with Lactobacillus plantarum also showed significantly increased blood leucocytes. In the present study, higher number of leucocytes in diet with highest concentration of the probiotic were recorded, while in other probiotic based groups, there was no statistically significant difference among white blood cell counts.

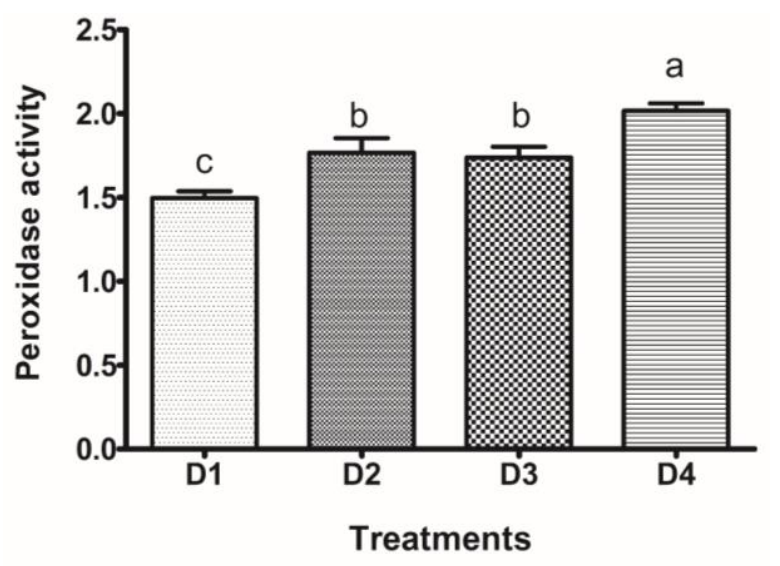

Figure 3. Effect of dietary Bacillus licheniformis supplementation on total serum peroxidase activity of Tilapia fingerlings. Variables with different superscript are significantly $(p<0.05)$ different statistically. D1 group was fed on basal diet, while D2, D3 and D4 fish groups were fed upon diet that included different levels of the probiotic, Bacillus licheniformis: $10^{5} \mathrm{CFU} / \mathrm{g}, 10^{7} \mathrm{CFU} / \mathrm{g}$, and $10^{9}$ $\mathrm{CFU} / \mathrm{g}$, respectively.

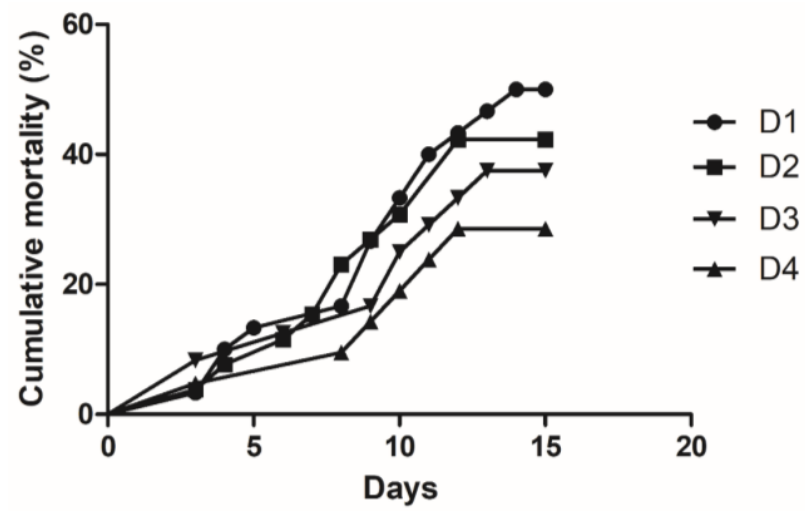

Figure 4. Cumulative percentage mortality of Tilapia fingerlings after challenged with S. aureus. (D1, fed on basal diet, while D2, $\mathrm{D} 3$ and D4, were fed upon diet including different levels of the probiotic, Bacillus licheniformis $10^{5} \mathrm{CFU} / \mathrm{g}, 10^{7} \mathrm{CFU} / \mathrm{g}$ and $10^{9} \mathrm{CFU} / \mathrm{g}$, respectively.) 
Other hematological parameters, such as hemoglobin concentration ( $\mathrm{HB})$, mean hemoglobin concentration (MHC), mean corpuscular hemoglobin concentration (MCHC) and Hematocrit (HCT) have not been documented previously with reference to $B$. licheniformis. In the present study, however, a significant increase in levels of these hemoglobin parameters were noticed indicating higher carrying capacity of oxygen in blood. Sufficient availability of oxygen to the fish ensures fish good health. Shareef and Dabbagh (2009) evaluated hemoglobin concentration in chicks when treated with yeast. Dahiya et al. (2012) had reported the effect of probiotics on hemoglobin parameters in the Indian Magur (Clarius Batrachus). Similarly, Firouzbakhsh et al. (2011) had determined similar parameters using protexin as a probiotic and reported increased levels of hemoglobin in the fingerlings.

\section{Enzyme Activity}

Lysozyme enzyme of fish's innate immune system works by prevention of biofilm formation and adherance of pathogens by stimulating a phagocytic activity. It disintegrates the polysaccharide cell wall of bacteria, and thus provides protection against pathogens. Nile Tilapia fed with increased probiotic concentration showed increase in lysozyme activity (Pirarat et al., 2011). Catla catla fed with probiotic $B$. amyloliquifaciens containing diet at concentration of $10^{8}$ and $10^{9}$ showed increased lysozyme activity (Das et al., 2013). In the present study, activity of lysozyme enzyme in the blood serum of Tilapia was significantly higher in fish treated with $B$. licheniformis containing diet. Further investigation to assess the lysozyme activity in mucus of fish fed with diets containing different probiotics is suggested.

The potential of $B$. licheniformis to increase the nutrient digestibility of aquatic organisms by stimulating enzymatic secretions, such as amylase, protease, cellulase has been documented in various aquatic organisms. Nejad et al. (2006) had reported elevated levels of these enzymes in Indian White Shrimp (Fenneropenaeus. indicus) by using Bacillus strains as probiotics. Similarly, Suzer et al. (2008) had reported increased activity of digestive enzymes in seabream when treated with Lactobacillus spp. as probiotic. Here, the increased levels of protease, amylase and lipase is the major reason for significant increase in growth rate. It seems that $B$. licheniformis, due to its high enzymatic potential, improves the absorption, digestion, and availability of given nutrients in an efficient way.

Effect of $B$. licheniformis to enhance phagocytic and respiratory burst activity of plasma in aquatic animals is less documented. In the present study, increased respiratory burst activity and phagocytic activity can cause enhanced bactericidal activity. Respiratory burst is associated with increased level of reactive oxygen species??? and free radicles which are associated with higher toxic levels for invading microbes. Also, this process is carried out by phagocytic cells which recognize any pathogens that enter the blood. Meidong et al. (2021) reported the increased respiratory burst activity in catfish when treated with Bacillus spp. probiotics. Similarly, Farnendes et al. (2021) reported increased respiratory burst activity in shrimp, when treated with different Bacillus spp. In the present study, the experimental diets have high rate of respiratory burst activity as compared to control diet which indicates increased metabolism and oxygen consumption through probiotic (B. lichniformis) supplementation.

\section{Challenge Test}

Use of probiotics in aquatic culture systems increases animal's resistance against potential pathogens; Gobi et al. (2016) reported challenge test with Aeromonas hydrophila in Tilapia using bacterial probiotic. Similarly, in the present study infection with staphylococcus aureus showed mortality in the control group, whereas probiotic-fed fish groups showed relatively lower mortality. Resistant to infection was due to modulated immune response, attained with $B$. licheniformis as a probiotic. With probiotic bacteria present in fish, pathogenic bacteria become weakened with less availability to nutrients as compared to probiotics. So, probiotic bacteria can compete with other invading microbes, making fish less susceptible to disease, and less prone to mortality.

The increase in growth rate can be attributed to increased digestive enzymatic activity, enhanced appetite, degradation of indigestible components as well as modulation of intestine morphology. There was an improvement in immune system which could be attributed to probiotic colony formation and adhesion to inner gut linig. Also, mucus and serum proteins levels were reported to be higher in fish with enhanced immune activity through probiotics.

This study describes the potential impacts of $B$. licheniformis on growth rate, survival rate, feed conversion ratio, hematological and immune parameters in 0 . mossambicus, when treated under controlled fish rearing conditions. The positive impact of the probiotic can be attributed to its vital role in enhancing digestibility and increasing enzymatic and cellular activities related to immune response and digestion. Based on these results, use of $B$. licheniformissupplemented diet can be considered as effective, ecofriendly, and viable practice to increase fish production in aquaculture of Tilapia and other fish species.

\section{Conclusion}

This study, in general, shows that Bacillus licheniformis is a potential probiotic for use in tilapia farming. When used with concentration of $10^{9} \mathrm{CFU} / \mathrm{g}$ in basal diet, it showed significant improvement in growth 
rate and feed conversion ratio. Also, with increasing concentration of probiotic in experimental diet, tilapia showed significant improvement in immunity. Hence, probiotic $B$. licheniformis can be used as alternative to other therapeutic and feed additives for sustainable aquaculture practices.

\section{Ethical Statement}

The handling of experimental animals (Tilapia juveniles) was performed in accordance with the recommendations in the international guiding principles for biomedical research involving animals (ICLAS, 2012). All manipulation was performed under anesthesia, and all efforts were made to minimize animal stress.

\section{Funding Information}

No specific funding was awarded to undertake this project.

\section{Author Contribution}

AY: Supervised the Project, approved the final version to be published.

MNA: Carried out experimental and laboratory work, Wrote the manuscript.

MK: Co supervised the Project, did statistical analysis, and contributed the final version of manuscript

$\mathrm{IM}$ : Conceived and planned the project, helped in experimental work.

\section{Conflict of Interest}

The author(s) declare that they have no known competing financial or non-financial, professional, or personal conflicts that could have appeared to influence the work reported in this paper.

\section{Acknowledgements}

We would like to thank Dr Arshad Ali (Professor Emeritus, Mid-Florida Research and Education Center, Florida Agricultural Experiment Station), Prof Dr Amina Zuberi (Fisheries and Aquaculture research station, Department of Zoology, Quaid I Azam University Islamabad) and Dr Imrana Amir (Lecturer Zoology, Education University (Attock campus) Lahore).

\section{References}

Acar, Ü., Kesbiç, O. S., Yılmaz, S., Gültepe, N., \& Türker, A. 2015. Evaluation of the effects of essential oil extracted from sweet orange peel (Citrus sinensis) on growth rate of Tilapia (Oreochromis mossambicus) and possible disease resistance against Streptococcus iniae. Aquaculture, 437: 282-286. https://doi.org/10.1016/j.aquaculture.2014.12.015

Adel, M., \& Dawood, M. A. (2021). Probiotics Application: Implications for Sustainable Aquaculture. Probiotic
Bacteria and Postbiotic Metabolites: Role in Animal and Human Health, 191-219.

Afridi, A. J., Zuberi, A., Yousafzai, A. M., Kamran, M., \& Ullah, S. 2019. Hemp (Marijuana) reverted Copper-induced toxic effects on the essential fatty acid profile of Labeo rohita and Cirrhinus mrigala. Molecular biology reports, 46(1), 391-401. https://doi.org/10.1007/s11033-0184483-2

Ahmad, M., Zuberi, A., Ali, M., Syed, A., Khan, A., \& Kamran, M. 2020. Effect of acclimated temperature on thermal tolerance, immune response and expression of HSP genes in Labeo rohita, Catla catla and their intergeneric hybrids. Journal of thermal biology, 89: 102570.

Aly, S. M., Mohamed, M. F., \& John, G. (2018). Effect of probiotics on the survival, growth and challenge infection in Tilapia nilotica (Oreochromis niloticus). Aquaculture research, 39(6), 647-656. https://doi.org/10.1111/j.1365-2109.2008.01932.x

Amir, I., Zuberi, A., Kamran, M., Imran, M \& Mahmood, U, M., 2019. Evaluation of commercial application of dietary encapsulated probiotic (Geotrichum candidum QAUGC01): Effect on growth and immunological indices of rohu (Labeo rohita, Hamilton 1822) in semi-intensive culture system. Fish \& Shellfish Immunology, 95: 464472

Basirun, A. A., Ahmad, S. A., Yasid, N. A., Sabullah, M. K., Daud, H. M., Sha'arani, S., ... \& Shukor, M. Y. 2019. Toxicological effects and behavioural and biochemical responses of Oreochromis mossambicus gills and its cholinesterase to copper: a biomarker application. International Journal of Environmental Science and Technology, 16(2):887-898.

Blanchard, J. L., Jennings, S., Holmes, R., Harle, J., Merino, G., Allen, J. I., ... \& Barange, M. 2012. Potential consequences of climate change for primary production and fish production in large marine ecosystems. Philosophical Transactions of the Royal Society B: Biological Sciences, 367(1605): 2979-2989. https://doi.org/10.1098/rstb.2012.0231

Bossier, P., \& Ekasari, J. 2017. Biofloc technology application in aquaculture to support sustainable development goals. Microbial biotechnology, 10(5): 1012-1016. https://doi.org/10.1111/1751-7915.12836

Bridson, P. B., Stoner, J. M., Fransen, M. H., \& Ireland, J. (2020). The aquaculture sustainability continuum-Defining an environmental performance framework. Environmental and Sustainability Indicators, 8, 100050.

Carvalho, D., Reyes, P., Williner, V., Mora, M. C., Viozzi, M. F., De Bonis, C. J., \& Collins, P. A. (2020). Growth, survival, body composition and amino acid profile of Macrobrachium borellii against the limitation of feeds with different $\mathrm{C}$ : $\mathrm{N}$ ratios with comments about application in integrated multi-trophic aquaculture. Aquaculture Research, 51(10), 3947-3958.

Civello, P. M., Martinez, G. A., Chaves, A. R., \& Anon, M. C. 1995. Peroxidase from strawberry fruit (Fragaria ananassa Duch.): partial purification and determination of some properties. Journal of agricultural and food chemistry, 43(10): 2596-2601. doi/pdfplus/10.1021/jf00058a008

Das, A., Nakhro, K., Chowdhury, S., \& Kamilya, D. 2013. Effects of potential probiotic Bacillus amyloliquifaciens FPTB16 on systemic and cutaneous mucosal immune responses and disease resistance of catla (Catla catla). Fish \& shellfish immunology, 35(5):1547-1553. https://doi.org/10.1016/j.fsi.2013.08.022 
Dawood, M. A., \& Koshio, S. 2016. Recent advances in the role of probiotics and prebiotics in carp aquaculture: a review. Aquaculture, 454: 243-251. https://doi.org/10.1016/j.aquaculture.2015.12.033

Dawood, M. A., Koshio, S., \& Esteban, M. Á. (2018). Beneficial roles of feed additives as immunostimulants in aquaculture: a review. Reviews in Aquaculture, 10(4), 950-974.

Devi, G., R. Harikrishnan, R., Paray, B. A., Al-Sadoon, M. K., Hoseinifar, S.H. \& Balasundaram, C. 2019. Comparative immunostimulatory effect of probiotics and prebiotics in Channa punctatus against Aphanomyces invadans, Fish Shellfish Immunol. 86: 965-973.

El-Saadony, M. T., Alagawany, M., Patra, A. K., Kar, I., Tiwari, R., Dawood, M. A., ... \& Abdel-Latif, H. M. (2021). The functionality of probiotics in aquaculture: An overview. Fish \& Shellfish Immunology.

Fernandes, S., Kerkar, S., D'Costa, A., Costa, M., Mishra, A., Shyama, S. K., \& Das, K. R. (2021). Immuno-stimulatory effect and toxicology studies of salt pan bacteria as probiotics to combat shrimp diseases in aquaculture. Fish \& Shellfish Immunology, 113, 69-78.

Firouzbakhsh, F., Noori, F., Khalesi, M. K., \& Jani-Khalili, K. 2011. Effects of a probiotic, protexin, on the growth performance and hematological parameters in the Oscar (Astronotus ocellatus) fingerlings. Fish Physiology and Biochemistry, 37(4): 833-842.

García-Medel, D. I., Angulo, C., Escamilla-Montes, R., FierroCoronado, J. A., Diarte-Plata, G., Gámez-Jiménez, C., \& Luna-González, A. (2020). Bacillus licheniformis BCR 4-3 increases immune response and survival of Litopenaeus vannamei challenged with Vibrio parahaemolyticus IPNGS16. Aquaculture International, 28(6), 2303-2318.

Gobi, N., Ramya, C., Vaseeharan, B., Malaikozhundan, B., Vijayakumar, S., Murugan, K., \& Benelli, G. 2016. Oreochromis mossambicus diet supplementation with Psidium guajava leaf extracts enhance growth, immune, antioxidant response and resistance to Aeromonas hydrophila. Fish \& shellfish immunology, 58: 572-583. https://doi.org/10.1016/j.fsi.2016.09.062

Gobi, N., Vaseeharan, B., Chen, J. C., Rekha, R., Vijayakumar, S., Anjugam, M., \& Iswarya, A. 2018. Dietary supplementation of probiotic Bacillus licheniformis Dahb1 improves growth performance, mucus and serum immune parameters, antioxidant enzyme activity as well as resistance against Aeromonas hydrophila in Tilapia Oreochromis mossambicus. Fish \& shellfish immunology, 74:

501-508. https://doi.org/10.1016/j.fsi.2017.12.066

Halwart, M. (2020). Fish farming high on the global food system agenda in 2020. FAO Aquaculture Newsletter, (61), II-III.

Hassaan, M. S., Mohammady, E. Y., Soaudy, M. R., Elashry, M. A., Moustafa, M. M., Wassel, M. A., ... \& Elsaied, H. E. (2021). Synergistic effects of Bacillus pumilus and exogenous protease on Nile Tilapia (Oreochromis niloticus) growth, gut microbes, immune response and gene expression fed plant protein diet. Animal Feed Science and Technology, 275, 114892.

Ibrar, M., Zuberi, A., Amir, I., Imran, M., \& Noor, Z. 2017. Effect of probiotic Geotrichum candidum on early rearing of Labeo rohita (Hamilton, 1822). Turkish Journal of Fisheries and Aquatic Sciences, 17(6): 1263-1270.

Iqbal, K. J., Qureshi, N. A., Ashraf, M., Rehman, M. H. U., Khan, N., Javid, A., ... \& Majeed, H. 2012. Effect of different salinity levels on growth and survival of Nile Tilapia (Oreochromis niloticus). The Journal of Animal and Plant Sciences, 22(4):

919-922. https://doi.org/10.1111/j.1365-2095.2009.00679.x

Jin, P., Tan, Z., Wang, H., Liu, W., \& Miao, W. (2021). Antimicrobial effect of Bacillus licheniformis $\mathrm{HN}-5$ bacitracin $A$ on rice pathogen Pantoea ananatis. BioControl, 66(2), 249-257.

Kalishwaralal, K., Deepak, V., Pandian, S. R. K., \& Gurunathan, S. 2009. Biological synthesis of gold nanocubes from Bacillus licheniformis. Bioresource technology, 100(21): 5356-5358. https://doi.org/10.1016/j.biortech.2009.05.051

Kamran, M., Yaqub, A., Malkani, N., Anjum, K. M., Awan, M. N., \& Paknejad, H. (2020). Identification and Phylogenetic Analysis of Channa Species from Riverine System of Pakistan Using COI Gene as a DNA Barcoding Marker. Journal of Bioresource Management, 7(2), 10.

Kim, J. K., Yarish, C., Hwang, E. K., Park, M., \& Kim, Y. (2017). Seaweed aquaculture: cultivation technologies, challenges and its ecosystem services. Algae, 32(1), 113.

Kuebutornye, F. K., Abarike, E. D., \& Lu, Y. (2019). A review on the application of Bacillus as probiotics in aquaculture. Fish \& shellfish immunology, 87, 820-828.

Kuebutornye, F. K., Wang, Z., Lu, Y., Abarike, E. D., Sakyi, M. E., Li, Y., ... \& Hlordzi, V. (2020). Effects of three hostassociated Bacillus species on mucosal immunity and gut health of Nile Tilapia, Oreochromis niloticus and its resistance against Aeromonas hydrophila infection. Fish \& shellfish immunology, 97, 83-95.

Liu, Q., Wen, L., Pan, X., Huang, Y., Du, X., Qin, J., ... \& Lin, Y. (2021). Dietary supplementation of Bacillus subtilis and Enterococcus faecalis can effectively improve the growth performance, immunity, and resistance of Tilapia against Streptococcus agalactiae. Aquaculture Nutrition.

Lu, Z., Yang, Q., Lin, Q., Wu, J., Du, H., \& Zhou, C. (2021). Effects of Bacillus spp. on growth, gut microbiota compositions and immunity of sea cucumber (Apostichopus japonicus). Aquaculture Research.

Mohammad, B. T., Al Daghistani, H. I., Jaouani, A., Abdel-Latif, S., \& Kennes, C. 2017. Isolation and characterization of thermophilic bacteria from Jordanian hot springs: Bacillus licheniformis and Thermomonas hydrothermalis isolates as potential producers of thermostable enzymes. International journal of microbiology, 2017. https://doi.org/10.1155/2017/6943952

Mohapatra, S., Chakraborty, T., Prusty, A. K., Das, P., Paniprasad, K., \& Mohanta, K. N. 2012. Use of different microbial probiotics in the diet of rohu, Labeo rohita fingerlings: effects on growth, nutrient digestibility and retention, digestive enzyme activities and intestinal microflora. Aquaculture Nutrition, 18(1):1-11. https://doi.org/10.1111/j.1365-2095.2011.00866.x

Monica, K. S., \& Jayaraj, E. G. (2021). Review on probiotics as a functional feed additive in aquaculture. (International journal o fisheries and aquatic sciences

Moustafa, E. M., Farrag, F. A., Dawood, M. A., Shahin, K., Hamza, A., Decamp, O., ... \& Omar, A. A. (2021). Efficacy of Bacillus probiotic mixture on the immunological responses and histopathological changes of Nile Tilapia (Oreochromis niloticus, L) challenged with Streptococcus iniae. Aquaculture Research, 52(5), 2205-2219.

Naiel, M. A., Shehata, A. M., Negm, S. S., Abd El-Hack, M. E., Amer, M. S., Khafaga, A. F., ... \& Allam, A. A. (2020). The 
new aspects of using some safe feed additives on alleviated imidacloprid toxicity in farmed fish: A review. Reviews in Aquaculture, 12(4), 2250-2267.

Naylor, R. L., Goldburg, R. J., Primavera, J. H., Kautsky, N., Beveridge, M. C., Clay, J., ... \& Troell, M. (2000). Effect of aquaculture on world fish supplies. Nature, 405(6790), 1017. https://doi.org/10.1038/35016500

Olmos, J., Acosta, M., Mendoza, G., \& Pitones, V. (2020). Bacillus subtilis, an ideal probiotic bacterium to shrimp and fish aquaculture that increase feed digestibility, prevent microbial diseases, and avoid water pollution. Archives of microbiology, 202(3), 427-435.

Pirarat, N., Pinpimai, K., Endo, M., Katagiri, T., Ponpornpisit, A., Chansue, N., \& Maita, M. 2011. Modulation of intestinal morphology and immunity in nile Tilapia (Oreochromis niloticus) by Lactobacillus rhamnosus GG. Research in veterinary science, 91(3): e92-e97. https://doi.org/10.1016/j.rvsc.2011.02.014

Qin, L., Xiang, J., Xiong, F., Wang, G., Zou, H., Li, W., ... \& Wu, S. (2020). Effects of Bacillus licheniformis on the growth, antioxidant capacity, intestinal barrier and disease resistance of grass carp (Ctenopharyngodon idella). Fish \& shellfish immunology, 97, 344-350.

Ring $\varnothing$, E., Van Doan, H., Lee, S. H., Soltani, M., Hoseinifar, S. H., Harikrishnan, R., \& Song, S. K. (2020). Probiotics, lactic acid bacteria and bacilli: interesting supplementation for aquaculture. Journal of applied microbiology, 129(1), 116-136.

Rodde, C., Chatain, B., Vandeputte, M., Trinh, T. Q., Benzie, J. A., \& De Verdal, H. (2020). Can individual feed conversion ratio at commercial size be predicted from juvenile performance in individually reared Nile Tilapia Oreochromis niloticus? Aquaculture Reports, 17, 10034 9.

Romanova, E., Spirina, E., Romanov, V., Lyubomirova, V., \& Shadyeva, L. (2020). Effects of Bacillus subtilis and Bacillus licheniformis on catfish in industrial aquaculture. In E3S Web of Conferences (Vol. 175, p. 02013). EDP Sciences.

Samson, J., Quiazon, K. M., \& Choresca, C. (2020). Application of probiotic Bacillus spp. isolated from African nightcrawler (Eudrilus eugeniae) on Nile Tilapia (Oreochromis niloticus L.). bioRxiv.

Seethalakshmi, P. S., Rajeev, R., Kiran, G. S., \& Selvin, J. (2021). Shrimp disease management for sustainable aquaculture: innovations from nanotechnology and biotechnology. Aquaculture International, 1-30.

Shah, S., Chesti, A., Rather, M., Hafeez, M., Aijaz, A., Yousuf, I., \& Jan, S. Effect of Probiotics (Bacillus subtilis) on the Growth and Survival of Fingerlings of Grass Carp, Ctenopharyngodon idella. (Journal of applied science and technology)

Shareef, A. M., \& Al-Dabbagh, A. S. A. 2009. Effect of probiotic (Saccharomyces cerevisiae) on performance of broiler chicks. Iraqi J Vet Sci, 23(Suppl I), 23-29.

Sheikhzadeh, N., Heidarieh, M., Pashaki, A. K., Nofouzi, K., Farshbafi, M. A., \& Akbari, M. 2012. Hilyses ${ }^{\circledR}$, fermented Saccharomyces cerevisiae, enhances the growth performance and skin non-specific immune parameters in rainbow trout (Oncorhynchus mykiss). Fish \& shellfish immunology, 32(6), 1083-1087. https://doi.org/10.1016/j.fsi.2012.03.003

Sookchaiyaporn, N., Srisapoome, P., Unajak, S., \& Areechon, N. (2020). Efficacy of Bacillus spp. isolated from Nile Tilapia Oreochromis niloticus Linn. on its growth and immunity, and control of pathogenic bacteria. Fisheries Science, 113.

Strzyzewska, E., Szarek, J., \& Babinska, I. (2016). Morphologic evaluation of the gills as a tool in the diagnostics of pathological conditions in fish and pollution in the aquatic environment: a review. Veterinarni Medicina, 61(3).

Strzyżewska-Worotyńska, E., Szarek, J., Babińska, I., \& Gulda, D. (2017). Gills as morphological biomarkers in extensive and intensive rainbow trout (Oncorhynchus mykiss, Walbaum 1792) production technologies. Environmental monitoring and assessment, 189(12), 1-9.

Sutthi, N., \& Van Doan, H. (2020). Saccharomyces crevices and Bacillus spp. effectively enhance health tolerance of Nile Tilapia under transportation stress. Aquaculture, 528, 735527.

Suzer, C., Çoban, D., Kamaci, H. O., Saka, Ş., Firat, K., Otgucuoğlu, Ö., \& Küçüksari, H. (2008). Lactobacillus spp. bacteria as probiotics in gilthead sea bream (Sparus aurata, L.) larvae: effects on growth performance and digestive enzyme activities. Aquaculture, 280(1-4), 140 145.

Tachibana, L., Telli, G. S., Dias, D. D. C., Gonçalves, G. S., Guimarães, M. C., Ishikawa, C. M., ... \& Ranzani-Paiva, M J. T. (2021). Bacillus subtilis and Bacillus licheniformis in diets for Nile Tilapia (Oreochromis niloticus): Effects on growth performance, gut microbiota modulation and innate immunology. Aquaculture Research, 52(4), 1630 1642.

Ullah, A., Zuberi, A., Ahmad, A., Bashir A., Shah, N. \& Younus, S. 2018. Dietary administration of the commercially available probiotics enhanced the survival, growth, and innate immune responses in Mori (Cirrhinus mrigala) in a natural earthen polyculture system, Fish Shellfish Immunol. 72 (2018) 266-272

Van Doan, H., Hoseinifar, S. H., Ring $\varnothing$, E., Ángeles Esteban, M., Dadar, M., Dawood, M. A., \& Faggio, C. (2020). Hostassociated probiotics: a key factor in sustainable aquaculture. Reviews in fisheries science \& aquaculture, 28(1), 16-42.

Vigneshwaran, C., Shanmugam, S., \& Kumar, T. S. (2010). Screening and characterization of keratinase from Bacillus licheniformis isolated from Namakkal poultry farm. Researcher, 2(4), 89-96.

Waiyamitra, P., Zoral, M. A., Saengtienchai, A., Luengnaruemitchai, A., Decamp, O., Gorgoglione, B., \& Surachetpong, W. (2020). Probiotics Modulate Tilapia Resistance and Immune Response against Tilapia Lake Virus Infection. Pathogens, 9(11), 919.

Wang, A., Ran, C., Wang, Y., Zhang, Z., Ding, Q., Yang, Y., ... \& Zhou, Z. (2019). Use of probiotics in aquaculture of China-a review of the past decade. Fish \& shellfish immunology, 86, 734-755.

Wang, M., Yi, M., Lu, M., Gao, F., Liu, Z., Huang, Q., ... \& Zhu, D. (2020). Effects of probiotics Bacillus cereus NY5 and Alcaligenes faecalis Y311 used as water additives on the microbiota and immune enzyme activities in three mucosal tissues in Nile Tilapia Oreochromis niloticus reared in outdoor tanks. Aquaculture Reports, 17 100309.

Won, S., Hamidoghli, A., Choi, W., Bae, J., Jang, W. J., Lee, S., \& Bai, S. C. (2020). Evaluation of potential probiotics Bacillus subtilis WB60, Pediococcus pentosaceus, and Lactococcus lactis on growth performance, immune 
response, gut histology and immune-related genes in whiteleg shrimp, Litopenaeus vannamei. Microorganisms, 8(2), 281.

Yaqub, A., Kamran. M., Malkani, N., Anjum, K. M., Faheem. M., Iqbal, M., Khan, R. U. (2019). Mitochondrial COI Gene Based Molecular Identification and Phylogenetic Analysis in Exotic Fish of Pakistan (Oreochromis Mossambicus). J Ani and Plant Sci, 29(5).

Zhang, D., Li, A., Guo, Y., Zhang, Q., Chen, X., \& Gong, X. (2013). Molecular characterization of Streptococcus agalactiae in diseased farmed Tilapia in China. Aquaculture, 412, 64-69. https://doi.org/10.1016/j.aquaculture.2013.07.014

Zhang, J., Huang, M., Feng, J., Chen, Y., Li, M., \& Chang, X. (2021). Effects of dietary Bacillus licheniformis on growth performance, intestinal morphology, intestinal microbiome, and disease resistance in common carp (Cyprinus carpio L.). Aquaculture International, 29(3), 1343-1358.

Zhou, Y., Yuan, X., Liang, X. F., Fang, L., Li, J., Guo, X., ... \& He, S. (2013). Enhancement of growth and intestinal flora in grass carp: the effect of exogenous cellulase. Aquaculture, 416, 1-7. https://doi.org/10.1016/j.aquaculture.2013.08.023

Ziaei-Nejad, S., Rezaei, M. H., Takami, G. A., Lovett, D. L., Mirvaghefi, A. R., \& Shakouri, M. 2006. The effect of Bacillus spp. bacteria used as probiotics on digestive enzyme activity, survival and growth in the Indian white shrimp Fenneropenaeus indicus. Aquaculture, 252(2-4): 516-524. 